\title{
LUZES VAGAS DE ESTRELAS: TEMPO E POESIA EM UM FILME DE VISCONTI
}

\section{Marcelo da Rocha Lima Diego}

Em 1965, Luchino Visconti filmou Vaghe Stelle dell'Orsa, com o qual ganhou, naquele mesmo ano, o seu primeiro Leão de Ouro do Festival de Cinema de Veneza. No título, a referência direta ao incipit do poema "Le ricordanze", de Giacomo Leopardi, propóe um desafio aos estudiosos da relação cinema-literatura: se são abundantes, na história da sétima arte, adaptações de romances, contos, peças de teatro e óperas, como pensar a gênese de um filme a partir de um poema? Mais: de um poema eminentemente lírico, sem traços épicos ou dramáticos? Este trabalho buscará, com apoio em algumas reflexões de Giorgio Agamben sobre as experiências do tempo, da poesia e da imagem, criar hipóteses sobre o processo de leitura, por parte de Visconti, do poema de Leopardi - ou: como o cineasta desentranhou, do poema, o filme.

Visconti era um leitor ávido e criativo, e todos os seus filmes apresentam elementos tomados de empréstimo ao repertório da literatura, seja anunciando-se como adaptaçôes, seja requestando determinada composição de personagem, certa peripécia da trama, alguma descrição de cenário. Até aquele ano, à exceção de Belissima e do curta-metragem Siamo donne - ambos discussões metassemióticas, posto que no primeiro a protagonista é uma aspirante a atriz, que deseja ter sucesso no cinema, e o segundo foi feito sob medida para a atriz Anna Magnani -, tudo o que havia filmado fora adaptaçôes de obras literárias: em Ossessione (1943), trouxe para a pianura padana o romance noir de James Cain The postman always rings twice; em La terra trema (episodio del mare) (1948), adensou a carga política já presente na novela I Malavoglia, de Giovanni Verga; em Senso (1954), apelou para todos os sentidos, através da ópera, apenas indiciada no romance de Camillo Boito; sua Le notti bianche (1957) se passa na Livorno do século XX, e não na São Petersburgo do XIX do conto de Dostoiévski; em Rocco e i suoi fratelli (1960), soma uma série de elementos marcadamente visuais à narrativa fragmentária de Il ponte della Ghisolfa, de Giovanni Testori; e no seu Il gattopardo (1963) efetuou violentos cortes na história criada por Tomasi di Lampedusa, apelando para o poder sintético 
das imagens que criou, as quais traduzem integralmente o espírito de decadência e imobilidade do livro. ${ }^{1}$

No filme de 1965, o roteiro original, escrito conjuntamente por Visconti e os companheiros de longa data Suso Cechi d'Amico e Enrico Medioli, aponta basicamente para duas inspiraçôes literárias: o poema de Leopardi, explicitado no título, e o mitologema grego de Electra e Orestes, aludido quer nas relações que permeiam as personagens, quer em cenas tomadas de empréstimo aos tragediógrafos que o eternizaram. Eis um resumo da trama: Sandra (Claudia Cardinale) e o marido Andrew (Michael Craig), que moram em Genebra, voltam para a cidade natal dela, Volterra, para uma homenagem ao pai, um cientista de origem judaica entregue ao extermínio nazista durante a Segunda Guerra Mundial; lá encontram o irmão de Sandra, Gianni (Jean Sorel), e vêm à tona os rumores acerca da suposta relação incestuosa que os dois mantinham quando jovens, a qual serve de tema a um livro que Gianni então escreve; Gianni tenta reconstituir a antiga relação que tinha com a irmã, mas, como Sandra se recusa a entrar no jogo fantasioso do irmão, este termina por se suicidar, no mesmo dia em que o é descerrada a herma do pai nos jardins da família - que são, naquela ocasião, doados à municipalidade - e em que Sandra decide se juntar ao marido, que fora para Nova Iorque.

A filiação ao mito grego fica clara na cena do encontro entre Sandra e Gianni aos pés da estátua do pai - ainda coberta por um pano (seu rosto jamais é mostrado, o pai existe apenas como nome, como ausência) -, que evoca a abertura das Coéforas, de Ésquilo, em que Electra, ao visitar a tumba de Agamêmnon, encontra Orestes. Como a heroína argiva, Sandra quer vingar a morte do pai - vai a Auschwitz investigá-la -, da qual julga culpada a mãe e seu amante - e futuro marido, Gilardini -, os quais acusa de terem-no delatado às autoridades nazistas. No entanto, enquanto no mito a cumplicidade entre Electra e Orestes se revela no esforço conjunto para vingar o pai, entre Sandra e Gianni a cumplicidade se faz presente em uma intimidade física, em uma dependência emocional por parte do irmão, em um passado impronunciável que insiste em se fazer ouvir à superfície. E, enquanto o mito se perfaz com o perdão no Aerópago e a purificação final, no filme a clau-

\footnotetext{
${ }^{1}$ Todas as informações a respeito da biografia e da trajetória do cineasta são respaldadas por: MICCHICHÉ, Lino. Luchino Visconti: un profilo critico. Veneza: Marsilio, 2006.
} 
" (AGAMBEN, Giorgio. A linguagem e a morte. Tradução de Henrique Burigo. Belo Horizonte: UFMG, 2006: 91-102.)

•(Ibidem: 101-111.) sura de Gianni no próprio passado culmina na impossibilidade de futuro, no suicídio.

Já a filiação ao poema de Leopardi é construída por um mecanismo de mise-en-abysme, como bonecas russas: o filme que conta a história de Sandra e Gianni leva o título do livro que, dentro do filme, conta a história de Sandra e Gianni, que por sua vez leva como título o incipit de um poema de Leopardi que também conta, em alguma medida, a história de Sandra e Gianni. Esse jogo de encaixamentos, para além da citação - convocação de outros textos pela qual se resgatam referências, relações e filiações -, parece lidar com uma solicitação que o filme faz de si mesmo - na qual ele, como escritura, se constrói enquanto busca da própria escritura.

Agamben, na sétima jornada de $A$ linguagem e a morte, remonta à retórica antiga e à instituição da tópica, "lugar de onde brota o discurso", erroneamente praticada como método mnemônico que facilita ao orador a retomada de argumentos, mas cuja possibilidade e meta original seria, através da ratio ou ars invenien$d i$ "método de descobrir"), ter acesso ao lugar onde brota a palavra, ou seja, resgatar na palavra a origem da linguagem. Se na retórica clássica a palavra já é um dado existente, cumprindo à inventio apenas resgatar o seu caráter originário, Agostinho, no Medievo, concebe a palavra como algo que brota justamente no gesto de buscar, identificando-a com o appetitus com que ela é buscada. Essa concepção da palavra não como aquilo que reside em determinado lugar e é buscado, mas como o desejo com que a palavra busca a si própria, foi a partilhada pelos trovadores provençais do século XII, que denominavam como amors o advento da palavra poética e o concebiam como a razo de trobar ("razão de trovar", sendo que na etimologia deste "trovar" está presente o sentido de "procurar"; it. "trovare", fr. "trouver") por excelência.

No mesmo texto, Agamben indica a vigência dessa concepção poética em Leopardi, por meio do exame do poema "Linfinito", em que, estruturalmente, a presença dos pronomes dêiticos "este" e "aquele", funcionando como shifters que revelam a existência do referente apenas como experiência na linguagem, inscreve a poesia em um lugar de memória e repetição no qual ela se volta sempre sobre si mesma. O mesmo ocorre em "Le ricordanze": as "lembranças" não são um referente que o texto retoma, mas as próprias experiências criadas pela experiência de criar o texto - até mesmo 
porque apenas aí elas existem enquanto lembranças. O passado é sempre aludido a partir de eventos situados no presente da escritura - que não pode ser confundido com o tempo em que Leopardi escreveu o poema, mas sim compreendido como toda vez que o poema é lido -, o que torna o poema uma constante procura desse passado idílico, o qual se encontra apenas nele. E, em vários momentos, textualmente, é a possibilidade de falar que dá acesso à possibilidade de lembrar: ${ }^{2}$

[...]; ma con dolor sottrenta

Il pensier del presente, un van desio

Del passato, ancor tristo, e il dire: io fui.

(vv. 58-60)*

[...]! sempre, parlando,

Ritorno a voi; [...]

(vv. 78-79)*

Visconti bebe a lição de Leopardi e filma Vaghe Stelle dell'Orsa como um filme à procura de si mesmo, movido pelo desejo da própria criação. Percebe-se-o na estratégia de caixa chinesa, por meio da qual a trama oferece seus próprios argumentos, mergulha intestinamente em um abismo intratextual; note-se que é apenas perto do fim do filme que Gianni declara ter encontrado o título para o seu livro em Leopardi, e que a destruição do livro se duplica na destruição de si mesmo, que se duplica ainda no encerramento do filme. Percebe-se-o, também, no seu autodesnudamento enquanto linguagem: operado com magistral sutileza com a assimilação, como trilha sonora, de uma música tocada em cena - o Prelúdio, Coral e Fuga, de César Franck, que perpassa todo o filme como trilha superposta, surge pela primeira vez na cena inicial do filme, quando é tocado pelo pianista na festa de Sandra e Andrew em Paris, e é retomado em cena novamente quando a mãe de Sandra e Gianni toca a peça na clínica em que está internada -; indicado com discrição na cena em que Andrew filma Sandra; e subsistente à própria opção de girar o filme em preto e branco, considerando que

\footnotetext{
${ }^{2}$ Neste artigo, todas as citações em italiano do poema de Leopardi serão feitas a partir da seguinte edição: LEOPARDI, Giacomo. Poesia e prose. A cura di Rolando Domiani e Mario Andrea Rigoni. Milano: Mondadori, 1998. E, em português, desta: LEOPARDI, Giacomo. "As lembranças". Tradução de José Paulo Paes. In: Giacomo Leopardi - poesia e prosa. Organização e notas de Marco Lucchesi. Traduçôes de Affonso Félix de Souza et al. Rio de Janeiro: Nova Aguilar, 1996.
}

• [...]; porém com dor assoma,

No pensar do presente, um vão desejo

De outrora, mesmo triste, e o dizer: fui. (vv. 57-59)

- [...] sempre, falando, A vós regresso, $[\ldots]$ (vv. 77-78) 
"Vagas estrelas da Ursa, eu não contava

Voltar ao hábito de vos olhar Sobre o pátrio jardim esplendoroso (vv. 1-3)

' [...]; e sob o pátrio teto Ouviam-se as conversas dos criados

(vv. 17-18)
• [...]. Pois não há coisa alguma

Que eu veja ou sinta sem que dela surja

Uma imagem ou doce remembrança. (vv. 54-56) o cinema em cores já era disponível e que Visconti já havia explorado a cor, deslumbrantemente, em Senso e Il gattopardo - o uso do preto e branco, após os avanços técnicos que permitiram o cinema colorido, torna-se um artificialismo que visa ressaltar a diferença entre representação e realidade e criar um vínculo direto com a história do cinema.

É possível reconstituir um - hipotético - caminho pelo qual Visconti recortou, na massa difusa do poema de Leopardi, as personagens Sandra e Gianni, bem como a perspectiva leopardiana sobre o tempo. Cumpre, todavia, observar com maior atenção cada um desses processos. "Le ricordanze" possui apenas duas personagens: o eu-lírico, que rememora, com nostalgia, os seus tempos de juventude, e Nerina, sua companheira quando jovem, a quem ele se dirige nas duas estrofes finais; na leitura aqui proposta, é o primeiro quem fornece traços para a composição de Gianni, e, a segunda, para Sandra.

O eu-lírico declara, logo de início, o inesperado retorno ao hábito de voltar à casa paterna -

Vaghe stelle dell'Orsa, io non credea

Tornare ancor per uso a contemplarvi

Sul paterno giardino scintillanti

(vv. 1-3)*

-, assim como Gianni declara que retorna a contragosto ao lar de sua infância (embora por outros motivos: o jovem volta periodicamente à casa de Volterra, abandonada, para saqueá-la). A voz dos servos é apaziguadora aos seus ouvidos -

Sonavan voci alterne, e le tranquille

Opre de' servi.[...]

(vv. 18-19)*

-, do mesmo modo que Fosca é cúmplice dos encontros de Gianni e Sandra. O olhar do eu-lírico estabelece uma dicotomia entre um passado maravilhoso, pleno de felicidades -

[...]. Qui non è cosa

Ch'io vegga o senta, onde un'immagin dentro

Non torni, e un dolce rimembrar non sorga

vv. $55-57^{\circ}$

- , e um presente infeliz -

[...]. E sebben vòti

Son gli anni miei, sebben deserto, oscuro 
Il mio stato mortal, poco mi toglie

La fortuna, bem veggo. [...]

(vv. 84-87)*

-; a mesma dicotomia se revela no esforço de Gianni em restaurar o passado, seja querendo dar continuidade à relação ambígua com a irmã, seja dedicando-se exaustivamente à recriação desse passado em seu romance.

O eu-lírico, repetidas vezes, diz preferir a morte à sua vida atual:

[...], e quante volte

Questa mia vita dolorosa e nuda

Volentier con la morte avrei cangiato.

(vv. 25-27)*

[...], e che la morte è quello

Che di cotanta speme oggi m'avanza.

(vv. 91-92)*

E quando pur questa invocata morte

Sarammi allato, e sara giunto il fine

Della sventura mia; [...].

(vv. 95-97)*

Morte chiamai più volte, $[. .$.

(v. 106) ${ }^{*}$

E assume ter chegado a por, deliberadamente, a vida em risco:

[...]. Poscia, per cieco

Malor, condotto della vita in forse,

(vv. 109-110)*

Gianni compartilha desse comportamento, o que é atestado

Mal em risco de vida co-

locado,

(vv. 108-109)

pela tentativa de suicídio, na infância (com o objetivo de chantagear a mãe e o padrasto para que o transferissem de escola), e pelo suicídio real, na maturidade.

Uma marca de Gianni é a arrogância: despe o torso na frente da irmã e do cunhado, vaidoso de sua beleza; ao revelar que vem rapinando os bens da família, a imagem que encontra para si é a de um falcão; exibe sua erudição declamando os versos de Leopardi e faz questão de perguntar a Andrew se conhece o poeta, apenas para humilhá-lo; almeja o sucesso literário, mesmo que à custa do escândalo da família; e, mais que tudo, confia plenamente em seu poder de persuasão, não se conforma com a nova vida da irmã e quer aliciá-la para o mundo fantasioso e nostálgico em que vive.

- E quando entanto esta invocada morte

Estiver a meu lado e o fim chegar

Da minha desventura; (vv. 95-97)

-Morte chamei mais vezes; (v. 105) 
* E menosprezador dos homens faço-me,

Pela grei que me cerca; [...] (vv. 41-42)

* [...] o mundo

A destra socorrente lhe oferece,

Perdoa-lhe os erros, saúda-lhe seu novo

Entrar na vida, e se curvando a ele

Mostra que por senhor o acolhe e chama? (vv. 125-129)
" [...], a tardas horas,

No cônscio leito, dolorosamente

A débil candeia poetando,

Lamentei com a noite e o

seu silêncio

O fugitivo espírito, e a mim mesmo

Sobre o languir cantei funéreo canto.

(vv. 112-117)
Também nessa arrogância se aproxima do eu-lírico de "Le ricordan$z e$ ", que despreza os homens ao seu redor -

E sprezzator degli uomini mi rendo,

Per la greggia ch'ho appresso:[...]

(vv. 42-43)*

-, a quem tudo tem que ser perdoado e a quem o mundo deve chamar de senhor:

[...] il mondo

La destra soccorerrevole gli porge,

Scusa gli errori suoi, festeggia il novo

Suo venir nella vita, ed inchinando

Mostra che per signor l'accolga e chiami?

(vv. 126-130)*

Um último ponto de encontro entre as personagens masculina de Visconti e de Leopardi a ser elencado é o refúgio na escrita; assim como Gianni, após o insucesso como jornalista, decide narrar a experiência de sua infância em um romance, também o eu-lírico de "Le ricordanze", ao perceber a pobreza de seus dias, escreve:

[...]: e spesso all'ore tarde, assiso

Sul conscio letto, dolorosamente

Alla fioca lucerna poetando,

Lamentai co' silenzi e con la notte

Il fuggitivo spirto, ed a me stesso

In sul languir cantai funereo canto.

(vv. 113-118)*

Através desse breve exame comparativo, ficam claras certas faces de Gianni que Visconti extrai da caracterização do eu-lírico do poema de Leopardi, como o retorno à casa paterna, o olhar nostálgico sobre o passado, a proximidade com a morte, a arrogância e o refúgio na escrita.

À Nerina não é dada voz no poema, que a evoca como morta, e a única caracterização possível da personagem é como objeto do discurso do eu-lírico. Não há, então, propriamente uma correlação entre Nerina e Sandra, mas sim um espelhamento da relação entre o eu-lírico e Nerina na relação entre Gianni e Sandra. O eu-lírico de Leopardi revela um sentimento obsessivo para com a memória de Nerina, tudo aponta para a sua ausência -

Ogni giorno sereno, ogni fiorita

Piaggia ch'io miro, ogni goder ch'io sento, 
Dico: Nerina or più non gode; i campo,

$\mathrm{L}^{\prime}$ aria non mira. [...]

(vv. 166-169)*

-; assim também Gianni, que nutre uma obsessão pela irmã e, face à recusa dela, ausenta-se da vida. Em uma leitura psicanalítica de Vaghe Stelle dell'Orsa, Renato Mezan* salienta que o caráter perverso de Gianni não reside em alguma prática incestuosa quiçá cometida na juventude com a irmã, mas em se encapsular nesse passado e se recusar a aceitar a nova vida de Sandra; seu sentimento é similar ao expresso no poema -

\section{[...]. Ahi Nerina! In cor mi regna}

L'antico amor. [...]

(vv. 157-158)*

-, no qual fica patente o anacronismo sentimental do eu-lírico. Por fim, nos últimos versos de "Le ricordanze", Nerina é descrita como

\section{[...] fia compagna}

D'ogni mio vago immaginar, di tutti

I miei teneri sensi, $[\ldots]$

(vv. 170-172)*

Talvez tenha sido nesse aspecto da relação do eu-lírico com Nerina, sua companheira juvenil no exercício da fantasia e dos "tenros sentidos", que Visconti leu uma possibilidade de relação incestuosa entre os dois, a qual transpôs para o filme tomando o cuidado de preservar sua ambiguidade.

Voltando agora o olhar para a noção de tempo presente no poema de Leopardi, esta assoma com um duplo estatuto - de diferença e de repetição. Por um lado, "Le ricordanze", com seu cunho memorialístico e nostálgico de um tempo pretérito, precipita-se em direção a um passado e o atualiza no presente, gerando uma experiência circular do tempo; enquanto subjetividade, o eu-lírico se encontra preso no círculo vicioso dessas lembranças, fora das quais é incapaz de divisar um horizonte de expectativas. Esse movimento de repetição, de retorno ao mesmo, se instaura, já no incipit, na requisição das estrelas como interlocutoras: "Vaghe Stelle dell'Orsa, io non credea". No repertório imagético da literatura, as estrelas ocupam, em diversas tradiçóes, lugar de destaque; na italiana, uma referência incontornável em que também aparecem com esse caráter de imutabilidade e testemunho é a Commedia de Dan-

Cada dia sereno, cada campo

Florido que olho, ou gozo que desfruto,

Faz-me dizer: Nerina já não goza

Os campos nem os ares, [...] (vv. 165-168)

" (MEZAN, Renato. "O ponto de fuga: sedução e incesto em Vaghe Stelle dell'Orsa...". In: Percurso $n^{\circ} 33$, fevereiro 2004. São Paulo: Departamento de Psicanálise, Instituto Sedes Sapientiae, 2004: 7-20.)

[ [...]. Ai Nerina! No meu peito

O amor antigo reina. [...] (vv. 156-157)

[...]: e fida Companhia do meu vago imaginar,

Do meu terno sentir, [...] (vv. 169-171) 
- (AGAMBEN, Giorgio. "O fim do poema". Tradução de Sérgio Alcides. Cacto 1. Edições Alpharrabio: Santo André (SP), 2002: 142-149. Texto publicado originalmente, sob o título "La fine del poema", in: AGAMBEN, Giorgio. Categorie italiane. Studi di poetica. Venezia: Marsilio, 1996: 113-119.)

- Vem o vento trazendo o som das horas

Desde a torre do burgo. (vv. 49-50)

"Aquela arcada ali, [...] (v. 60) te, na qual tanto o "Inferno" quanto o "Purgatório" e o "Paradiso" se encerram com o vocábulo "stelle" - configurando uma espécie de epístrofe, ou, conforme pontua Agamben em "O fim do poema”, clavis. ${ }^{*}$ Mais especificamente, as estrelas da Ursa Maior remetem a outra referência igualmente incontornável, Heráclito, que no fragmento 120 posiciona esses astros como solitárias testemunhas da ventura humana: "Os limites da aurora e do crepúsculo são a Ursa e, frente à Ursa, o limite do sereno Zeus”.

Por outro lado, no poema de Leopardi as estrelas da Ursa não são apenas imutáveis, mas parecem igualmente refletir-se nas águas, sempre as mesmas e sempre outras, daquele rio de que Heráclito também fala. De dentro da repetição irrompe a diferença: os mesmos shifters que direcionam o poema, enquanto subjetividade do eu-lírico, para um retorno ao antigo - a materialidade do passado comprovada, por exemplo, na evocação do

Viene il vento recando il suon dell'ora

Dalla torre del borgo.

(vv. 50-51)

ou de

\section{Quella loggia cola, $[\ldots]$}

(v. 61)*

direcionam-no igualmente, enquanto instância discursiva, para um abertura ao sem-fim, para uma "torre del borgo" ou uma "loggia" feitas novas à cada leitura, para uma inscrição do poema no plano da memória - "órgão de modalização do real" que possibilita uma projeção interminável.

Visconti soube captar e transpor para a linguagem do cinema a complexa noção de tempo presente em Leopardi. A cena inicial do filme, a da festa em Genebra, funciona como um prólogo; apenas apresenta a heroína, mostra sua nova vida, desconexa da temporalidade em que o filme se dará, e dá a nota (literalmente - a peça de Franck) que afinará toda a orquestração da obra. O primeiro movimento do filme, de fato - sua "overture" -, é mergulho no passado, filmado com mestria por Visconti na cena da viagem de Genebra a Volterra, de carro: o espectador sofre um empuxo para dentro da tela, seguindo o movimento vertiginoso da câmera na estrada; a edição das curvas cria a perspectiva de um caminho espiralado, rumo a um centro inalcançável; e os túneis, atuando como sucessivos portais, geram a sensação de aprofundamento. Che- 
gando a Volterra, o passado parece reificado, torna-se tátil: Sandra entra na casa, passeia pelos cômodos, toca os móveis, retorna ao cenário de sua infância e, quando Fosca diz ter preparado para ela e o marido o quarto de hóspedes, prefere dormir no seu quarto de solteira, sozinha. Trancado, o quarto da mãe permanece intacto, como se o tempo houvesse parado, como parado está o relógio de Eros e Psique que lá existe; nele, como quando era criança, ainda se esconde um bilhete do irmão. Este, por seu turno - como já foi observado mais atentamente -, também se esforça para retornar ao passado, restaurando os velhos hábitos.

O filme esboça, assim, o desenho de um tempo circular, mas rompe essa circularidade com a presença de vetores que assinalam, na repetição, a diferença. Andrew, o marido de Sandra, é quem carrega os principais signos de abertura ao futuro: é estrangeiro, manipula novas tecnologias - como o carro esporte e a filmadora - e, ao casar com Sandra, é quem a tira de uma ordem familiar, na qual desempenhava o papel de filha e irmã, para localizá-la em outra, onde é mulher e poderá ser mãe. Sandra, ela mesma, concentra em si o estatuto duplo da temporalidade: continua sendo a mesma pessoa, mas não quer dar continuidade a certos hábitos do passado. O local em que Visconti situou a história contribui nesse sentido, pois Volterra se ergue sobre colinas geologicamente instáveis, sendo comum a ocorrência de deslizamentos, o que não desestimula as novas geraçôes a continuar construindo seus edifícios nos mesmos locais. Assim, a paisagem da cidade - uma das mais antigas da península itálica, de origem etrusca - está em constante alteração (em escala histórica), e, fadadas a um fim não distante, as novas construções já nascem com um caráter de ruína.

Tanto o poema de Leopardi quanto o filme de Visconti falam de um tempo passado a partir da abertura que esse tempo oferece para o presente e o futuro, ou seja, através de "uma singular relação com o próprio tempo, que adere a este e, ao mesmo e tempo, toma distância dele", que se situa em relação a ele "através de uma defasagem e de um anacronismo". As citações do Agamben de "O que é o contemporâneo?"3 já revelam aonde se quer chegar: à experiência de contemporaneidade presente em Vaghe Stelle dell'Orsa.

\footnotetext{
${ }^{3} \mathrm{O}$ texto de Agamben aqui utilizado é aquele da tradução, não publicada, de Cláudio Oliveira, a partir da lição inaugural do curso de Filosofia Teorética 20062007 do IUAV de Veneza. Há, contudo, uma edição brasileira do texto, com a qual esta pode ser confrontada: AGAMBEN, Giorgio. O que é o contemporâneo? e outros ensaios. Tradução de Vinícius Honesko. Chapecó (SC): Argos, 2009.
} 
O filósofo italiano, no texto mencionado acima, faz algumas proposições sobre o que seja ser contemporâneo, para além de uma perspectiva meramente cronológica; a todas elas subjaz a percepção de uma experiência de fratura, de desvio, de ruptura da homogeneidade. Ser contemporâneo não é enxergar apenas as luzes de seu tempo, mas o escuro desse mesmo tempo; não se deixar ofuscar pela claridade e apreender o que está na obscuridade. Ser contemporâneo não é ver apenas a luz pontual das estrelas no céu noturno, mas perceber a escuridão como a luz de galáxias inteiras que não consegue chegar ao nosso sistema, porque ele se afasta delas em velocidade ainda maior. Ser contemporâneo é, ainda, compreender o próprio tempo naquilo em que é arcaico, isto é, próximo à arké, a origem. Por isso, sintetiza Agamben, "a via de acesso ao presente tem sempre a forma de uma arqueologia".

Arqueologia é o que realiza Visconti em seu filme, ao resgatar o originário operante no complexo das relaçōes que medeiam as personagens. Arqueologia que, aliás, é evocada enquanto técnica quando Gilardini, no museu da cidade, entre objetos funerários etruscos, conversa com Andrew e oferece, ele também, resquícios de outras épocas, vestígios da relação entre Sandra e Gianni. Os dois irmãos, por sua vez, também escavam cenicamente o passado ao descerem à cisterna da casa, seu esconderijo quando crianças; nessa catábase, caminham entre sombras - uma lembrança se esconde atrás de cada pilastra; um fantasma, em cada reflexo na poça d'água - e, face aos sentimentos exumados, cada um segue um caminho: Sandra volta ao mundo dos vivos para continuar sua jornada (Nova Iorque será sua Ítaca), ao passo que Gianni prefere habitar entre espectros.

O foco do filme não está no que acontece claramente no presente da ação, mas no que se esconde em sua sombra, no que é "resistente" (no sentido psicanalítico, aquilo que não se deixa apreender e elaborar); seu foco é essa penumbra, o passado que Gianni tenta fazer presente, mas do qual Sandra se afasta ainda mais rápido. Para dar conta desse foco, Visconti - contemporaneamente - dispóe de múltiplos tempos, coloca-os em jogo uns com os outros, interpola-os: as urnas funerárias etruscas, os mitos gregos, o palazzo renascentista, a poesia romântica, os nazistas e o carro esporte, todos os tempos ressurgem à luz do tempo de agora. Recorrendo a uma das imagens agambenianas para o contemporâneo - a de enxergar no escuro da noite a luz de galáxias distantes que não conseguem 
chegar à Terra -, percebe-se como, ao contrário de Gianni, que vê apenas as stelle d'Orsa, o filme - e nisso se identifica com o olhar de Sandra (não por acaso o título em inglês, através do qual o filme se difundiu pelo mundo, é Sandra) - busca captar o que há de vaghe nelas. A constelação da Ursa Maior, composta por sete estrelas, é visível durante todo o ano no hemisfério celestial norte e por isso foi, desde a astronomia antiga - na Mesopotâmia, no Egito, na Grécia e na China, entre outras -, utilizada como ponto de referência para estudos astronômicos e para localização marítima. Historicamente, portanto, sua semântica está ligada à determinação, mas tanto Leopardi quanto, mais ainda, Visconti, poeticamente, trazem para o primeiro plano - é a primeira palavra do verso o seu caráter de indeterminação; donde se pode ler, no dístico inicial do poema, uma hipálage: não são as estrelas da Ursa que se caracterizam pela vagueza, mas o ato de contemplá-las.

Resta ainda um ponto a investigar na relação entre "Le ricordanze" e Vaghe Stelle dell'Orsa: se Visconti pode fazer um filme a partir de um poema é porque soube perceber a proximidade entre os estatutos poético e cinematográfico. Também Agamben aproximou essas duas instâncias ao atribuir aos institutos caracterizadores de ambas essas linguagens a condição transcendental da interrupção.

No poema, tal natureza disjuntiva se verifica na necessária asseveração da possibilidade do enjambement, o qual opõe um limite métrico ao limite sintático; ali, no local preciso da versura, o fim de uma cadeia sonora deixa em suspenso uma cadeia de sentido, promovendo uma hesitação entre o semiótico e o semântico que distingue a poesia da prosa e que restaura o hibridismo originário do discurso humano. Ao passo que no fim do verso é o enjambement que promove esse salto da voz sobre o abismo do sentido, no meio do verso é a cesura que, pondo-lhe um freio súbito, chama a atenção para sua materialidade como pura palavra; como quando uma cena de filme se congela - a comparação não é fortuita... - e o encadeamento narrativo cede a vez à constatação, no still, de que se trata simplesmente de uma imagem. Seja no meio, seja no fim do verso - na cesura ou no enjambement-, o poético se revela em um movimento suspensivo que torna manifesta a própria representação e a natureza da linguagem.

Já no cinema, a montagem se constitui como dispositivo intrínseco e apresenta dois recursos: a repetição e a paragem. A repetição interrompe a narração em seu fluxo linear e torna nova-
- (Cf. AGAMBEN, Giorgio. Idée de la prose. Paris: Christian Bourgois, 1998: 21-27.)

- (Cf. AGAMBEN, Giorgio. "O cinema de Guy Debord". Tradução não creditada. Disponível em: $<$ http://intermidias.blogspot.com/2007/07/o-cinema-de-guy-debord-de-giorgio.html> Acesso em: 29.06.2010. Texto originalmente publicado sob o título "Le cinéma de Guy Debord", in: AGAMBEN, Giorgio. Image et mémoire. Paris: Hoëbke, 1998: 65-76.) 
mente presente algo que já está ausente, restaura sua possibilidade de existência; assimilando esse mecanismo próprio da memória, a repetição torna indiscerníveis, no discurso, o real e o possível. A paragem igualmente interrompe o fluxo da narrativa, mas não na linearidade, e sim em sua ilusão de realidade; a pausa, o corte, o salto expõem a imagem naquilo em que ela é puro meio. Assim, a imagem cinematográfica, trabalhada pela montagem, opera, como a poesia, um processo de autodesnudamento da representação em que se faz presente toda a potência da linguagem humana.

As reflexões de Agamben, entrelaçando as condições fundamentais do poema e do filme, dão ensejo à formulação de uma poesia cinematográfica e de um cinema de poesia. Tanto a voz da poesia, abismando-se sempre em direção a um futuro e a um passado, quanto a imagem do cinema, assimilando o movimento e inserindo-se, assim, em uma continuidade, compartilham da natureza de gesto; e, como gesto, abertura a um antes e um depois, "consiste[m] em exibir uma mediação, em tornar visível um meio como tal". ${ }^{4}$ Daí, na transposição intersemiótica que realiza, Visconti ter conseguido atualizar toda a potência da poesia de Leopardi na potência própria do cinema. Não apenas desentranhou, do poema, as personagens e a trama, mas também a noção de tempo; e transfigurou a experiência da voz poética na experiência da imagem-movimento. Obra inaugural, obra-prima.

\section{Marcelo da Rocha Lima Diego}

Mestrando em Literatura Comparada na UFRJ, com bolsa da CAPES, e assistente editorial na revista eletrônica Machado de Assis em linha. É graduado em Letras (Português-Literaturas) pela UFRJ e está em fase de conclusão de sua segunda graduação, em Artes (História da Arte), na UERJ. Em 2007 e 2008, foi bolsista de Iniciação Científica do CNPq na Fundação Casa de Rui Barbosa; e, em 2009, trabalhou como professor substituto do Departamento de Ciência da Literatura da UFRJ.

Palavras-chave: cinema; literatura; poesia italiana; adaptação.

\section{Resumo}

Em 1965, Luchino Visconti filmou Vaghe Stelle dell'Orsa. No título, a referência direta ao incipit do poema "Le ricordanze", de

${ }^{4}$ AGAMBEN, Giorgio. Moyens sans fins: notes sur la politique. Paris: Payot et Rivages, 1995: 69. Tradução do autor. No original: "Le geste consiste à exhiber une medialité, à rendre visible un moyen comme tel." 
Giacomo Leopardi, propõe um desafio aos estudiosos da relação cinema-literatura: se são abundantes, na história da sétima arte, adaptações de romances, contos, peças de teatro e óperas, como pensar a gênese de um filme a partir de um poema? Este trabalho buscará, com apoio em algumas reflexões de Giorgio Agamben sobre as experiências do tempo, da poesia e da imagem, criar hipóteses sobre o processo de leitura, por parte de Visconti, do poema de Leopardi - ou: como o cineasta desentranhou, do poema, o filme.

\section{Abstract}

In 1965 Luchino Visconti filmed Vaghe Stelle dell'Orsa (Sandra of a Thousand Delights, or simply Sandra, in UK and US). The title makes a clear reference to the incipit of Giacomo Leopardi's poem "Le ricordanze" ("Remembrances"), proposing a challenge to the researchers on the relationship between film and literature: in the history of film, adaptations from novels, short stories, plays and operas are quite frequently; but how to think a poem as the source of a movie? Based on Giorgio Agamben's thoughts about experiencing time, poetry and image, this paper aims to understand the way Visconti read Leopardi's poem - or, in other words: the way the director unravelled a movie from a poem.

\section{Riassunto}

Nel 1965 Luchino Visconti girò il film Vaghe Stelle dell'Orsa. Nel titolo, il riferimento diretto allo incipit della poesia "Le ricordanze”, di Giacomo Leopardi, propone una sfida agli studiosi della relazione tra cinema e letteratura: poichè nella storia della settima arte sono così numerosi gli adattamenti di romanzi, racconti, testi teatrali ed opere, come pensare la genesi di un film a partire da una poesia? Questo saggio cercherà, anche grazie al supporto di alcune riflessioni di Giorgio Agamben circa le esperienze del tempo, della poesia e dell'immagine, di creare delle ipotesi sul processo di lettura da parte di Visconti riguardo il canto di Leopardi - ovvero: come il cineasta riesce ad estrarre il film dall'intimo della poesia.
Key words: film; literature; Italian poetry; adaptation.

Parole-chiave: cinema; letteratura; poesia italiana; adattamento. 